\title{
Kinetic Modeling on Nozzle Clogging During Steel Billet Continuous Casting
}

\author{
Mujun LONG, ${ }^{1)}$ Xiangjun ZUO, ${ }^{2)}$ Lifeng ZHANG ${ }^{3)}$ and Dengfu CHEN ${ }^{4)}$ \\ 1) Visiting Scholar, Department of Materials Science and Engineering, Missouri University of Science and Technology \\ (Missouri S\&T), USA. Ph.D Student, College of Materials Science and Engineering, Chongqing University, P.R. China. \\ 2) Ph.D Student, Department of Materials Science and Engineering, Missouri University of Science and Technology (Missouri \\ S\&T), USA. $\quad 3)$ Assistant Professor, Department of Materials Science and Engineering, Missouri University of Science \\ and Technology (Missouri S\&T), 223 McNutt Hall, Rolla, MO 65409-0340, USA. E-mail: zhanglife@mst.edu 4) Formerly \\ Visiting Scholar, Department of Materials Science and Engineering, Missouri University of Science and Technology (Missouri \\ S\&T), USA. Now at College of Materials Science and Engineering, Chongqing University, P.R. China.
}

(Received on December 17, 2009; accepted on February 13, 2010)

\begin{abstract}
In the current paper, a kinetic model was developed to study the entrapment of inclusions in the molten steel flowing through a Submerged Entry Nozzle (SEN) during billet continuous casting process. The trajectory of inclusions was calculated by considering the drag force, lift force and gravitational force. The entrapment locations of inclusions on SEN wall were predicted. The effects of nozzle diameter, casting speed, billet dimension, and inclusion diameter on SEN clogging were quantitatively discussed. The results indicate the inclusions with diameter larger than $100 \mu \mathrm{m}$ are not able to be entrapped by the nozzle wall; and the entrapment probability will increase quickly with decreasing size of inclusions. The distribution of the entrapped inclusions along the nozzle length is non-uniform and the volume fraction of inclusions in the clogging materials should be considered in order to more precisely predict the accumulated weight of molten steel that can be poured before the nozzle is fully blocked by clogging. Under the conditions assumed: $150 \mathrm{~mm} \times 150 \mathrm{~mm}$ billet, $2.0 \mathrm{~m} / \mathrm{min}$ casting speed, approximately $25^{\circ} \mathrm{C}$ superheat, $1 \mathrm{~m}$ length of the SEN $\left(\mathrm{Al}_{2} \mathrm{O}_{3}-\mathrm{C}\right.$ materials), $20 \mu \mathrm{m}$ inclusions diameter in a single size, $30 \mathrm{ppm}$ T.O and $40 \mathrm{~mm}$ nozzle diameters, the prediction shows that $\sim 351$ ton steel can be poured for the current billet continuous caster.
\end{abstract}

KEY WORDS: nozzle clogging; steel continuous casting; inclusions; fluid flow; kinetic model.

\section{Introduction}

The Submerged Entry Nozzle (SEN) is used between the tundish and the mold during steel continuous casting process. The function of SEN is to prevent the molten steel from being oxidated, decrease the emulsification of the top surface of the mold and lower the air absorption during casting. SEN clogging has been a long term problem for steel continuous casting process. ${ }^{1-30)}$ Causes and prevention of SEN clogging were extensively reviewed by Kemeny, ${ }^{20)}$ Thomas, ${ }^{23)}$ Cramb, ${ }^{11)}$ and the current author Zhang. ${ }^{2,31)}$ Inclusion accretions, especially alumina inclusions for Alkilled steel, CaS inclusions for Ca-treatment steel and TiN inclusions for Ti-killed steels, are the main reason for the clogging. ${ }^{1)}$ Inclusions moving in the molten steel through the nozzle may be entrapped once they walk close to the lining refractory. It was reported that clogging occurs preferentially at the locations where the stagnation and separation of the flow occur within the SEN. ${ }^{32)}$ Thus, investigating the fluid flow and the motion of inclusions in the nozzle is important to understand the fundamentals of the SEN clogging. The kinetic study of SEN clogging has been reported by Mukai et al. ${ }^{33)}$ and Zhang et al. ${ }^{2,4)}$ Based on the previous studies, the kinetic model for the SEN clogging was devel- oped in the current paper to investigate 1) trajectory of the inclusions in the flowing molten steel in the nozzle; 2) entrapment of inclusions to the nozzle wall under different conditions; and 3) prediction of the accumulated weight of molten steel that can be poured before the nozzle is blocked by the clogging materials.

\section{Model Formulation}

The model developed here is based on the study by Mukai et al., ${ }^{33)}$ by which the classical empirical fluid flow velocity distribution in a pipe including that in the boundary layer was used and then the trajectory of inclusions were calculated by considering different forces acting on them in the fluid. Compared with the model developed by Mukai et al., the current study has the following improvements:

- The thickness of the transition layer and laminar sublayer are not fixed but varies with the fluid flow velocity in the pipe, while the fluid flow velocity depends on the casting speed and the dimension of the continuous casting billet. The roughness of the wall is considered.

- The injection of inclusions is not just from $300 \mu \mathrm{m}$ away from the wall that was assumed by Mukai's model, but 
from the entire cross section of the pipe.

- The suitable time step for solving the trajectory equation of inclusions is discussed in detail.

- The effects of inclusion size, casting speed, nozzle diameter, billet dimension, and the total oxygen in the steel on the entrapment of inclusions and the entrapment criterion are discussed.

- The accumulated weight of molten steel that can be poured before the SEN is blocked by the clogging materials is predicted, the fraction of inclusion in the clogging materials and the non-uniform distribution of inclusions entrapped along the nozzle height are considered and discussed in the current paper.

For a billet continuous casting process, a bottom open SEN is usually used, just like a pipe. Though the inner diameter of the SEN at the top is a little different from the bottom, the turbulent pipe flow condition in the SEN is assumed. There are three zones of the fluid flow in the pipe: turbulent bulk zone, transition layer and laminar sub-layer, as shown in Fig. 1. The distribution of the velocity and the turbulent diffusion coefficient can be represented by Eqs. (1) $-(8)^{34)}$ :

In the turbulent bulk zone $\left(y^{+}>30\right)$

$$
\begin{aligned}
& \bar{u}_{f}^{+}=\frac{\bar{u}_{f}\left(r_{p}, t\right)}{u^{*}}=2.5 \ln \left(y^{+}\right)+5.5 \\
& D_{t}=19.04 \mu_{f} / \rho_{f}
\end{aligned}
$$

In the transition layer $\left(30>y^{+}>5\right)$

$$
\begin{gathered}
\bar{u}_{f}^{+}=\frac{\bar{u}_{f}\left(r_{p}, t\right)}{u^{*}}=5.0 \ln \left(y^{+}\right)+3.05 \\
D_{t}=\left(y^{+} / 5-0.959\right) \mu_{f} / \rho_{f} \ldots \ldots
\end{gathered}
$$

In the laminar sub-layer $\left(y^{+}<5\right)$

$$
\begin{gathered}
\bar{u}_{f}^{+}=\frac{\bar{u}_{f}\left(r_{p}, t\right)}{u^{*}}=y^{+} . \\
D_{t}=\left(y^{+} / 14.5\right)^{3} \mu_{f} / \rho_{f}
\end{gathered}
$$

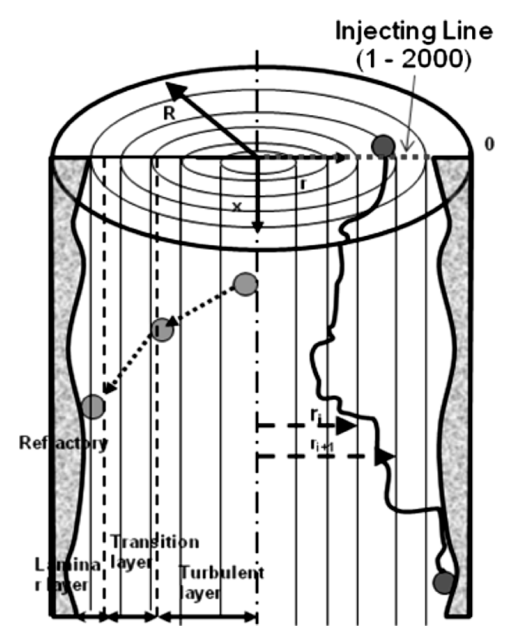

Fig. 1. Schematic of the fluid flow and motion of inclusions in a pipe nozzle. where $u_{f}^{+}$is the dimensionless velocity of the fluid flow; $D_{t}$ is the turbulent diffusion coefficient with different values in the turbulent bulk and boundary layers; $\bar{u}_{f}\left(r_{p}, t\right)$ is the mean fluid phase velocity in $\mathrm{m} / \mathrm{s} ; r_{p}$ is the distance of inclusion particles from nozzle center in radial direction ( $r$ direction) in meter; $t$ is the time in second; $u^{*}$ is the friction velocity in $\mathrm{m} / \mathrm{s} ; \mu_{f}$ is the kinetic viscosity coefficient in $\mathrm{Pa} \cdot \mathrm{s} ; \rho_{f}$ is the density of the molten steel in $\mathrm{kg} / \mathrm{m}^{3} ; y^{+}$is the dimensionless distance of the fluid flow in the pipe represented by:

$$
y^{+}=u^{*} \rho_{f}\left(R-r_{p}\right) / \mu_{f}
$$

where $R$ is the radius of the nozzle in meter; $u^{*}$ is the friction velocity in $\mathrm{m} / \mathrm{s}$, which can be calculated by

$$
u^{*}=\sqrt{\frac{\tau_{0}}{\rho_{f}}}=u_{f, \text { bulk }} \sqrt{\frac{f}{8}}
$$

where $\tau_{o}$ is the shearing force at wall $\left(\mathrm{N} / \mathrm{m}^{2}\right) ; u_{f \text {,bulk }}$ is the mean velocity of molten steel in the nozzle in $\mathrm{m} / \mathrm{s} ; f$ is the dimensionless friction factor derived by Darcy, it should be mentioned here this friction factor is four times of that by Fanning. ${ }^{35)}$ The value of $f$ is a function of Reynolds number of the flow in the pipe $\left(\operatorname{Re}=D \cdot u_{\mathrm{bulk}} \cdot \mu / \rho_{f}\right)$ and wall roughness, as shown in Fig. 2. ${ }^{35)}$ In the current model, the effect of roughness can be included. For the current stage, it is assumed the roughness to be zero. Qualitatively, more inclusions would be entrapped onto the nozzle lining wall with larger roughness. The quantitative effect of roughness on the entrapment of inclusions to the nozzle lining wall will be performed in depth in the future.

Inclusions enter the SEN together with the molten steel from the tundish. Due to the forces acting on the inclusions, they move not only along the longitudinal direction but also the transverse direction of the pipe, and may move from the turbulent bulk zone to the transition layer and the laminar sub-layer, and may be captured by the lining refractory wall.

The forces acting on a particle moving in a pipe include gravitational force, drag force, lift force, virtual mass force and pressure gradiatent force. ${ }^{36)}$ For the current molten steel-inclusions-SEN system, the current study has revealed that the effect of the virtual mass force and pressure gradiatent force is less than $0.5 \%$, thus these two forces are ignored. The location of inclusions can be calculated by inter-

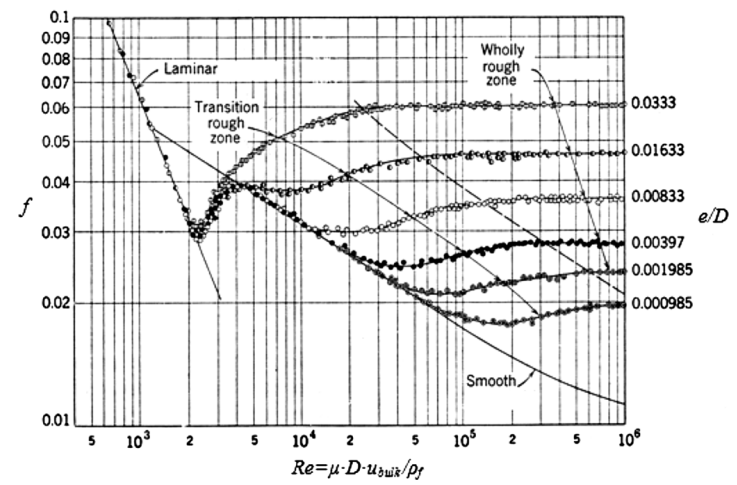

Fig. 2. Relationship between friction factor and Reynolds number for the flow in the pipe (Re) and wall roughness $(e / D)$. 
grating the velocity of the inclusions over time by the equations below.

Motion equation of inclusions in $x$ direction (longitudinal direction of the pipe):

$$
\begin{aligned}
& \frac{d x_{p}}{d t}=u_{p} \\
& \frac{d u_{p}}{d t}=\frac{3}{4} \frac{1}{d_{p}} \frac{\rho_{f}}{\rho_{p}} \frac{24}{\operatorname{Re}_{p}}\left(u_{f}-u_{p}\right)^{2} \frac{u_{f}-u_{p}}{\left|u_{f}-u_{p}\right|} \\
& -\frac{\left(\rho_{f}-\rho_{p}\right)}{\rho_{p}} g \\
& \mathrm{Re}=\rho_{f} d_{p}\left|u_{f}-u_{p}\right| / \mu_{f}
\end{aligned}
$$

Motion equation of incusions in $r$ direction (radial direction of the pipe):

$$
\begin{aligned}
& \frac{d r_{p}}{d t}=v_{p} \\
& \frac{d v_{p}}{d t}=\frac{3}{4} \frac{1}{d_{p}} \frac{\rho_{f}}{\rho_{p}} \frac{24}{\operatorname{Re}}\left(v_{p}-v_{f}\right)^{2} \frac{v_{f}-v_{p}}{\left|v_{f}-v_{p}\right|}+\frac{F_{L}}{\pi d_{p}^{3} \rho_{p} / 6} \\
& \operatorname{Re}_{p}=\rho_{f} d_{p}\left|v_{f}-v_{p}\right| / \mu_{f}
\end{aligned}
$$

where $x_{p}$ and $r_{p}$ is the distance of inclusion particles in $x$ and $r$ direction in meter; $u_{p}$ and $v_{p}$ are the velocity of inclusions in $x$ and $r$ direction in $\mathrm{m} / \mathrm{s} ; t$ is the time in $\mathrm{s} ; d_{p}$ is the diameter of the particles in meter; $u_{f}$ and $v_{f}$ are the velocity of molten steel in $x$ and $r$ direction in $\mathrm{m} / \mathrm{s} ; \rho_{p}$ is the density of inclusions in $\mathrm{kg} / \mathrm{m}^{3} ; g$ is the gravitational acceleration; $F_{L}$ is the lift force acting on the inclusion.

The Saffman lift force is expressed by

$$
\begin{gathered}
F_{L}=1.62 \mu_{f} d_{p}\left(u_{f}-u_{p}\right) \sqrt{\operatorname{Re}_{G}} \\
\operatorname{Re}_{G}=\frac{\rho_{f} d_{p}^{2}}{\mu_{f}} \cdot\left|\frac{\partial u_{f}}{\partial r_{p}}\right| \ldots \ldots \ldots \ldots . . .
\end{gathered}
$$

The initial velocity of the inclusion at the entrance of the nozzle is expressed by

$$
\begin{aligned}
u_{p}\left(r_{p}, t=0\right)= & u_{f}\left(r_{p}, t=0\right)-\frac{d_{p}^{2} g\left(\rho_{f}-\rho_{p}\right)}{18 \mu_{f}} \ldots \ldots \\
& v_{p}\left(r_{p}, t=0\right)=v_{p}^{\prime} \ldots \ldots \ldots \ldots \ldots \ldots \ldots \ldots \ldots \ldots \ldots \ldots \ldots \ldots
\end{aligned}
$$

The instantaneous velocity of the fluid flow is expressed by

$$
\begin{array}{r}
u_{f}\left(r_{p}, t\right)=\bar{u}_{f}\left(r_{p}, t\right)+u_{f}^{\prime} \\
v_{f}\left(r_{p}, t\right)=v_{f}^{\prime} \ldots \ldots \ldots \ldots
\end{array}
$$

where $u_{f}^{\prime}$ and $v_{f}^{\prime}$ is the turbulent velocity fluctuation in $x$ and $r$ direction in $\mathrm{m} / \mathrm{s}$, which is expressed by

$$
u_{f}^{\prime}=v_{f}^{\prime}=v_{p}^{\prime}=1.49 \zeta \frac{D_{t}}{0.4\left(R-r_{p}\right)}
$$

where $\xi$ is a Gaussian-distributed random number; $D_{t}$ is the turbulent diffusion coefficient with different values in the turbulent bulk and boundary layers, as shown in Eqs. (2), (4) and (6). ${ }^{17)}$

In order to more precisely predict the entrapment of inclusions from entire cross section of the pipe to nozzle wall, two thousand inclusions are injected into the nozzle along the radius of the nozzle entrance. Then the trajectories of inclusions were calculated, and the entrapment locations of inclusions are predicted.

\section{Results and Discussion}

\subsection{Discussion of the Entrapment Criterion}

A simple entrapment criterion is used here: 1) for the case that the thickness of the laminar sub-layer is larger than the inclusion radius, the inclusion is entrapped if its center enters the laminar sub-layer; 2) for the case that the thickness of the laminar sub-layer is less than the inclusion radius, the inclusion is entrapped if the distance between the wall and the inclusion center equals its radius. The entrapment criterion can be expressed as below:

$$
\left(R-r_{p}\right) \leq\left\{\begin{array}{l}
L \\
\frac{d_{p}}{2}+e
\end{array}\right.
$$

where $R$ is radius of the nozzle in meter; $r_{p}$ is distance from the inclusion center to nozzle center in meter; $L$ is the thickness of laminar layer in meter; $e$ is the roughness of the nozzle in meter.

It has been observed that there are frozen steel net form structures generated on the surface of the nozzle lining refractory, as shown in Fig. 3. Lots of $\mathrm{Al}_{2} \mathrm{O}_{3}$ inclusions (dendrites and clusters) entrapped inside the hole of the net form structures. The holes of the net form are in dimension of approximately $1 \mathrm{~mm}$, thus, once inclusions (usually less than $50 \mu \mathrm{m}$ ) enter these holes they will be entrapped. Thus the current entrapment criterion is reasonable.

\subsection{Determination of the Time Step}

The motion of inclusions is stochastic in the turbulent flow of the molten steel inside the SEN. The Lagrangian stochastic model for the motion of particles in fluid flow has been reported. ${ }^{37-43)}$ For the stochastic model, the time step is very important since it has a great effect on the trajectory of the particle. In the current paper, several different time steps were tried. The results indicated that since the fluid flow inside the SEN was assumed to be in a steady state in the current paper, a variable time step should be used, as that is used in Fluent software. The time step $\Delta t$ used in the current model can be expressed by:

$$
\Delta t=\min \left(\frac{L_{s}}{\left|v_{f}-v_{p}\right|}, \frac{L_{s}}{\left|u_{f}-u_{p}\right|}\right)
$$

where $L_{s}$ is the length scale of $3.0 \mu \mathrm{m}$. Since the relative velocity between the fluid flow and the inclusion motion may be very small at some times, the time step will be quite big 


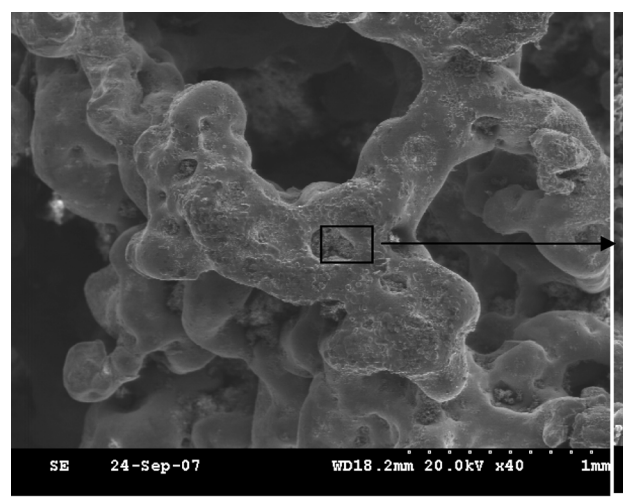

(a) steel foam covered with $\mathrm{Al}_{2} \mathrm{O}_{3}$ inclusions

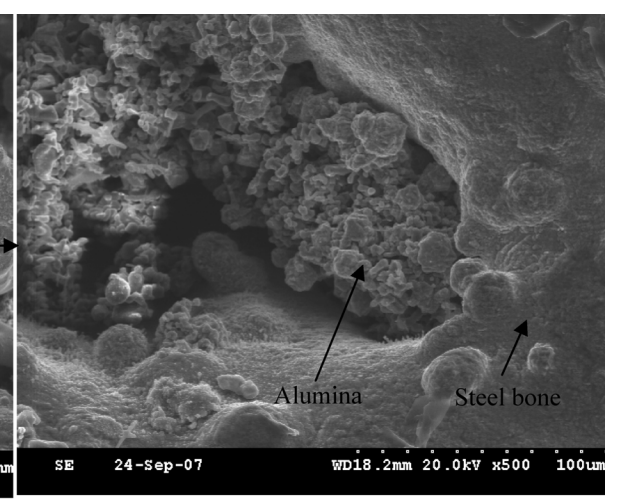

(b) $\mathrm{Al}_{2} \mathrm{O}_{3}$ inclusions in the pores of steel foam

Fig. 3. Inclusions entrapped in the steel net form structure on the surface of SEN.

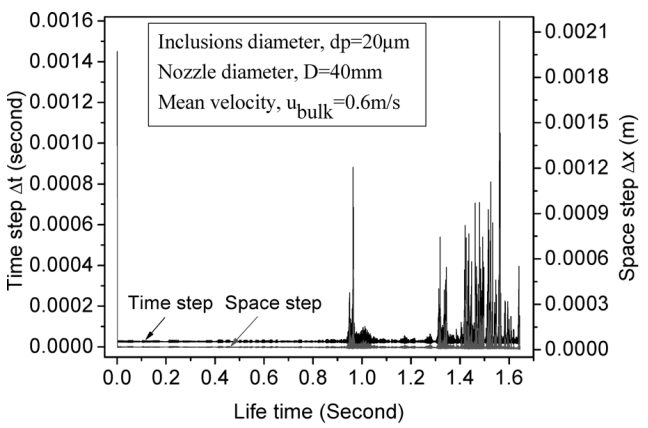

(a) time step $\Delta \mathrm{t}$ and space step $\Delta \mathrm{x}$

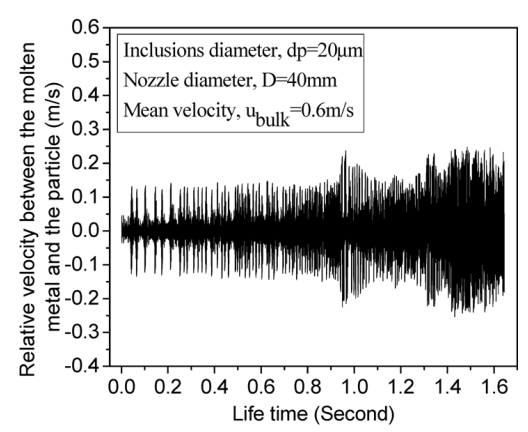

(b) the relative velocity: $u_{f}-u_{p}$

Fig. 4. The time step, space step and relative velocity between molten metal and particle during the life time of the particle.

and thus the particle may move a long distance in one time step, which will lead to a wrong result. Thus, in the current study, the space step that the inclusion moves in one time step is required to be less than $1.0 \mathrm{~mm}$. Figure 4 shows the example relative velocity between the molten metal, space step and the time step used during the life time of the particle in the system.

\subsection{Trajectory of Inclusions}

In the current paper, the entrapment of inclusions in the $\mathrm{SEN}\left(\mathrm{Al}_{2} \mathrm{O}_{3}-\mathrm{C}\right.$ materials $)$ with of a $150 \mathrm{~mm} \times 150 \mathrm{~mm}$ billet continuous caster was simulated. The inner diameter of the SEN is $40 \mathrm{~mm}$, and the mean velocity in the nozzle is $0.6 \mathrm{~m} / \mathrm{s}$, corresponding to a $2.0 \mathrm{~m} / \mathrm{min}$ casting speed, superheat is $25^{\circ} \mathrm{C}$. It is calculated that the thickness of the laminar sub-layer $(L)$ is $0.13 \mathrm{~mm}$ under this condition. Two thousand inclusions were injected along the radius of the nozzle entrance; No. 1 particle is the one at the center of the nozzle entrance, while No. 2000 is the one close to the lining refractory wall. Example trajectories of $20 \mu \mathrm{m}$ inclusions were shown in Fig. 5. When inclusions are injected close to the SEN center (at the turbulent bulk zone), the motion of inclusions is more random. The fluctuation becomes smaller once the inclusion walks close to the wall or enter the SEN through the transition layer. As indicated, No. 99 and No. 550 inclusions, which were released far from the nozzle wall, were not entrapped to the nozzle wall, but the other four inclusions were entrapped.

\subsection{Discussion on Entrapment Probability}

In the current paper, the entrapment probability of inclu-
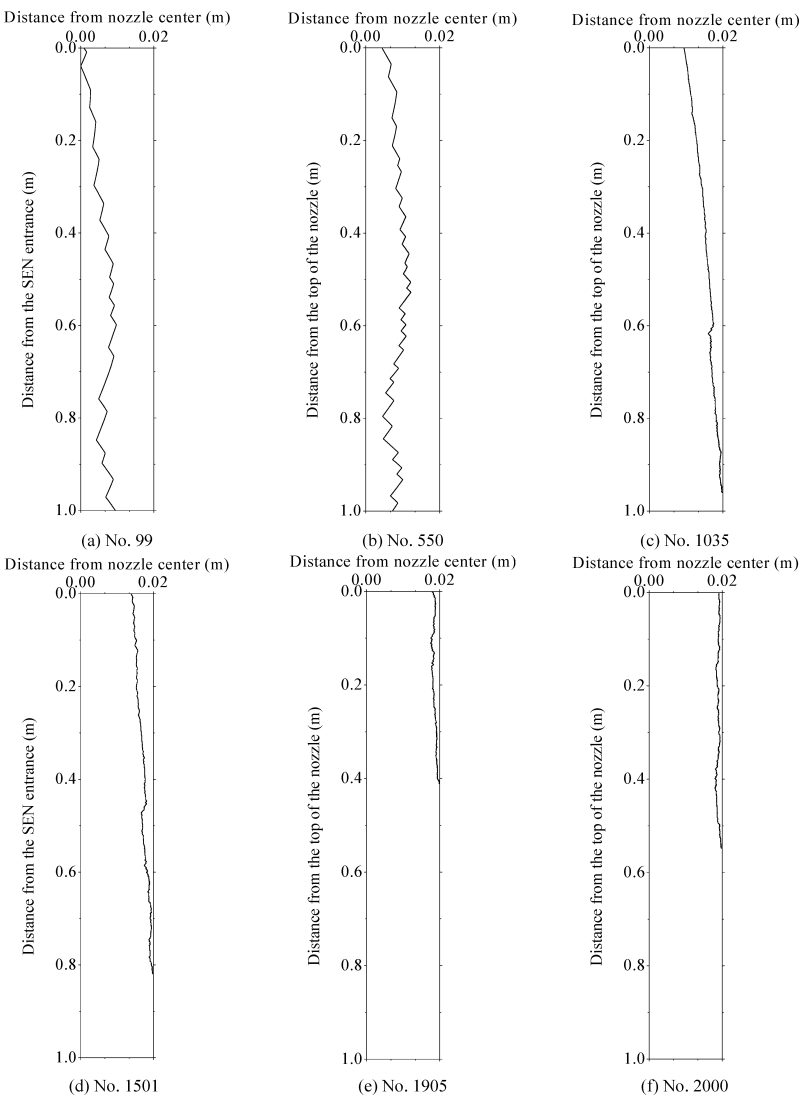

Fig. 5. Trajectories of inclusions injected from different locations at the SEN entrance. 
sions to the SEN wall is defined by Fig. 1 and Eq. (24)

$$
P=\sum_{i} p_{i}=\frac{\sum_{i}\left[\frac{N_{0, i}}{N_{t, i}}\left(\pi\left(R_{i}+\Delta R\right)^{2}-\pi R_{i}^{2}\right)\right]}{\frac{\pi}{4} D^{2}}
$$

where $N_{0, i}$ is the number of inclusions entrapped by the SEN wall, $N_{t, i}$ is the total number of inclusions injected through the entrance area $A_{i}$; and $i$ is the sequence number of the annular position at which inclusions are injected. $R$ is the radial distance from the nozzle center; $D$ is the diameter of the nozzle in meter. Many factors have effect on the entrapment probability, such as the position from which inclusions are injected, size of inclusions, diameter of the SEN, casting speed, and the dimension of the billet.

Figure 6 shows the dependency of the entrapment probability on the size of inclusions. Smaller inclusions are easier to be entrapped by the nozzle wall. Inclusions larger than $100 \mu \mathrm{m}$ are impossible to be entrapped. If the bulk velocity in the nozzle is $0.6 \mathrm{~m} / \mathrm{s}$ and the nozzle is with a $40 \mathrm{~mm}$ diameter, the total entrapment probability for $10 \mu \mathrm{m}, 20 \mu \mathrm{m}$, $40 \mu \mathrm{m}, 60 \mu \mathrm{m}$ and $80 \mu \mathrm{m}$ are $46.26 \%, 18.57 \%, 9.53 \%$, $10.59 \%$ and $2.93 \%$ respectively, which indicates the entrapment probability of inclusions increases quickly with decreasing size of inclusions if inclusions were smaller than $15 \mu \mathrm{m}$.

The velocity of the molten steel at the locations close to the nozzle center is larger than that close to the wall (as shown in Fig. 7), due to which the inclusions at the locations close to the nozzle center are more difficult to be entrapped by nozzle wall. Thus the entrapment probabilities of inclusions are diverse while injected from different loca-

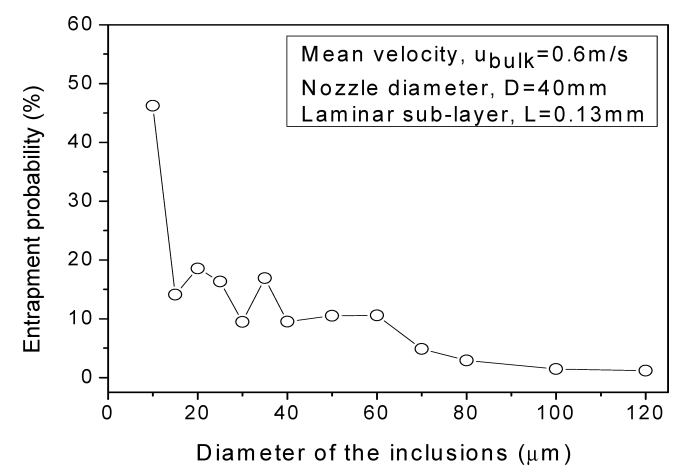

Fig. 6. Relationship between the entrapment probability and the size of inclusions.

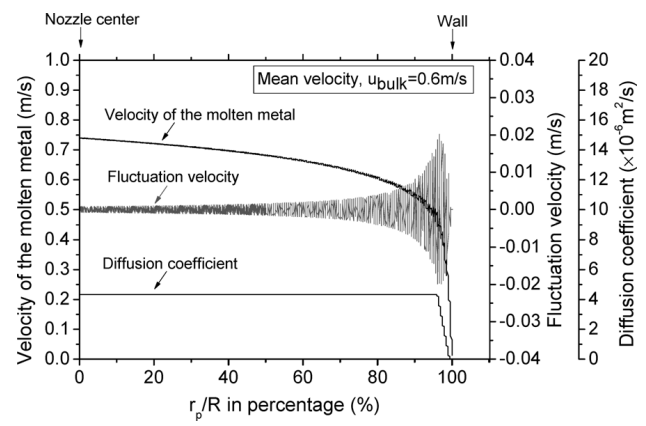

Fig. 7. Distribution of velocity, fluctuation velocity and the diffusion coefficient. tions. Entrapment probability of inclusions versus the injection location of inclusions is shown in Fig. 8. The entrapment probability close to the wall is far larger than that close to the center. Inclusions injected from the nozzle center have the smallest entrapment probability. For $10 \mu \mathrm{m}$ inclusions, they may finally be entrapped by the nozzle wall even though being injected from the nozzle center. While $>20 \mu \mathrm{m}$ inclusions are hardly entrapped to the nozzle wall when they are injected from the nozzle center.

The effect of SEN inner diameter on the entrapment probability is shown in Fig. 9. With the same bulk velocity, larger inner diameter nozzle implies a higher casting speed. Since the friction factor decreases with larger inner diameter of the nozzle (Fig. 2), thus the larger diameter nozzle has lower entrapment probability. Thus, with the casting speed, smaller diameter SEN entraps more inclusions. For $20 \mu \mathrm{m}$ inclusions moving in the molten steel inside a SEN
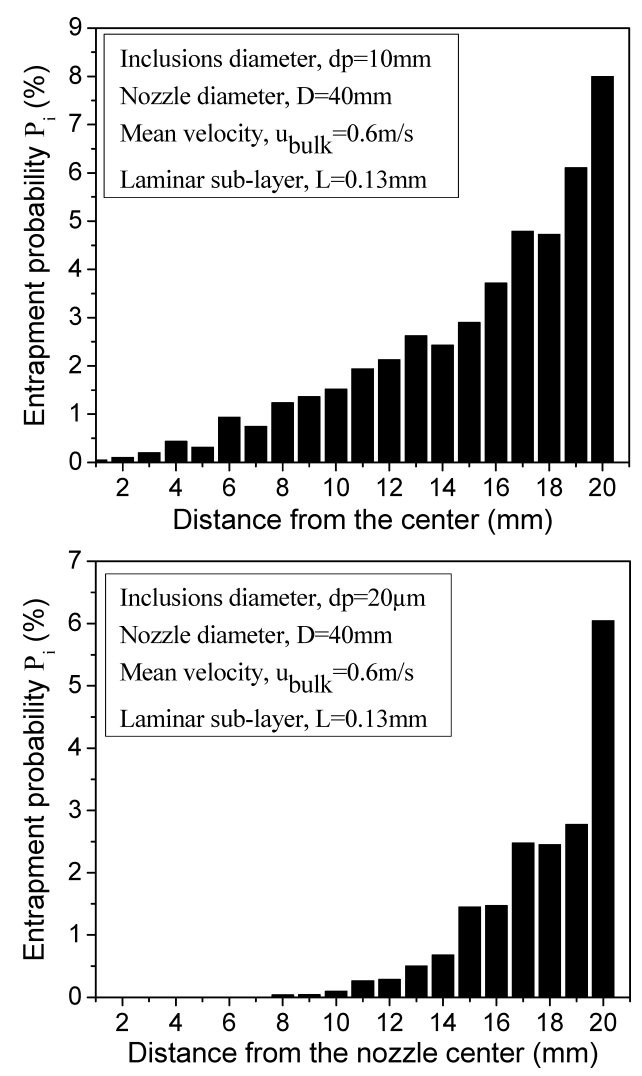

Fig. 8. Entrapment probability of inclusions injected from different locations at the SEN entrance.

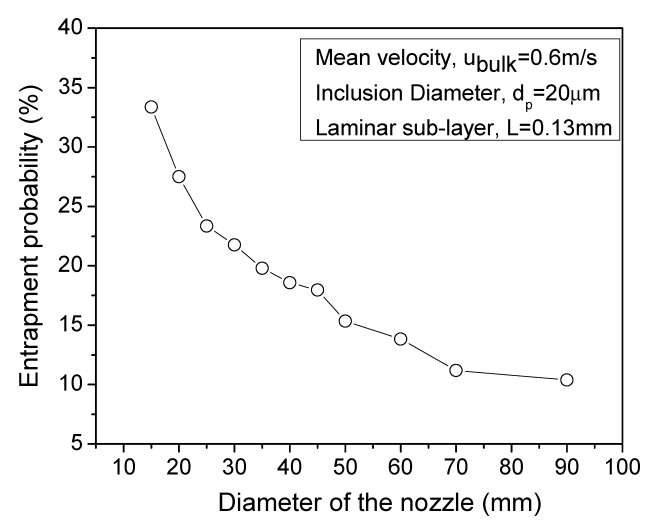

Fig. 9. Effect of nozzle diameter on the entrapment probability. 
with $0.6 \mathrm{~m} / \mathrm{s}$ bulk velocity, the SEN with $40 \mathrm{~mm}$ diameter entraps $18.57 \%$ inclusions, while those with $20 \mathrm{~mm}, 60 \mathrm{~mm}$ and $90 \mathrm{~mm}$ diameter SENs entraps $27.49 \%, 13.83 \%$, and $10.39 \%$ inclusions respectively. From Fig. 9, the following regression equation can be obtained between the entrapment probability and the inner diameter of the SEN

$$
P=2.14 \cdot D^{-0.66}
$$

The current model indicates that smaller bulk velocity induces higher entrapment probability of inclusions to the SEN wall, as shown in Fig. 10. Under certain conditions ( $20 \mu \mathrm{m}$ inclusions and $40 \mathrm{~mm}$ inner diameter of the SEN), the entrapment probability with $0.6 \mathrm{~m} / \mathrm{s}$ bulk velocity is $18.57 \%$, while is $29.96 \%, 14.37 \%, 9.12 \%$ respectively for those with $0.4 \mathrm{~m} / \mathrm{s}, 0.8 \mathrm{~m} / \mathrm{s}$, and $1.0 \mathrm{~m} / \mathrm{s}$ bulk velocity. The following simple regression equation is obtained,

$$
P=64.76 \exp \left(-2.03 u_{\text {bulk }}\right)
$$

The relationship between the bulk velocity, inner diameter of the SEN, billet dimension and casting speed can be expressed by

$$
u_{\text {bulk }} \times \frac{\pi}{4} D^{2} \times \rho_{f}=\rho_{s} \times a \times b \times \frac{V_{c}}{60}
$$

where $V_{c}$ is the casting speed in $\mathrm{m} / \mathrm{min}, a$ and $b$ are the dimensions of the casting strand in $\mathrm{m}, \rho_{s}$ is the density of solid steel density $\left(7800 \mathrm{~kg} / \mathrm{m}^{3}\right)$ and $\rho_{f}$ is the density of

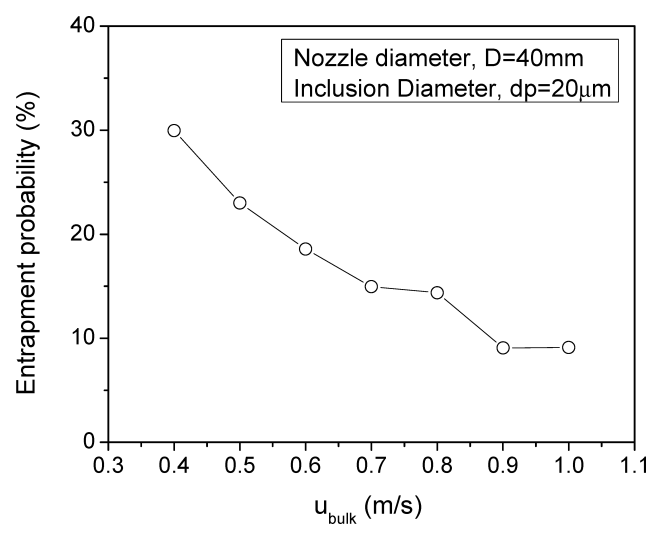

Fig. 10. Effect of the bulk speed in the SEN on the entrapment probability.

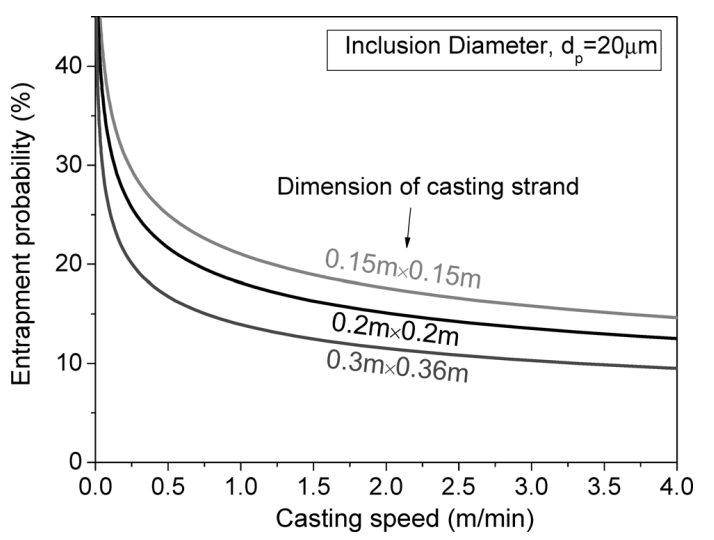

Fig. 11. Relationship between casting speed and inclusion entrapment probability. molten steel $\left(7020 \mathrm{~kg} / \mathrm{m}^{3}\right)$.

According to Eqs. (25)-(27), the relationship between casting speed $V_{c}$ and the entrapment probability $P$ can be written as:

$$
V_{c}=-\frac{209.5}{a \times b} \times P^{-3.03} \times \ln (P / 64.76)
$$

For a $150 \mathrm{~mm} \times 150 \mathrm{~mm}$ billet continuous caster, the entrapment probability of inclusions as a function of casting speed to the SEN nozzle wall is illustrated in Fig. 11, indicating that smaller casting speed entraps more inclusions to the nozzle wall. At the same casting speed, the entrapment probability of inclusions is lower for the larger dimension casting strand.

\subsection{Entrapment Probability along the Nozzle Length}

The number of inclusions entrapped along the vertical distance from the SEN entrance is quite different, as shown in Fig. 12. In industry, the diameter of nozzle at the entrance is larger than that at the bottom, and argon gas may be injected from the upper nozzle. In the current model, the diameters of the nozzle at the entrance and the bottom were assumed to be the same and the effect of the argon injection was ignored, so the SEN wall entraps inclusions the most close to the entrance shown in the result. Except the nozzle entrance, inclusions entrapped to the nozzle wall slightly increases along the downward length of the SEN. This is because inclusions move longer time after they enter the SEN before being finally entrapped. The location entrapping more inclusions will be entirely clogged first, which implies that it may only some location of the nozzle is fully clogged by inclusions while other places still have free spaces. This fact has to be accounted for the prediction of the accumulated weight of molten steel that can be poured before the nozzle is blocked. In the current paper, the entirely blocking at the location where entraps the most inclusions was used to judge how much molten steel can be poured.

\subsection{Prediction of the Accumulated Weight of Molten Steel that Can be Poured for a SEN}

Different bath depth in the tundish results in different

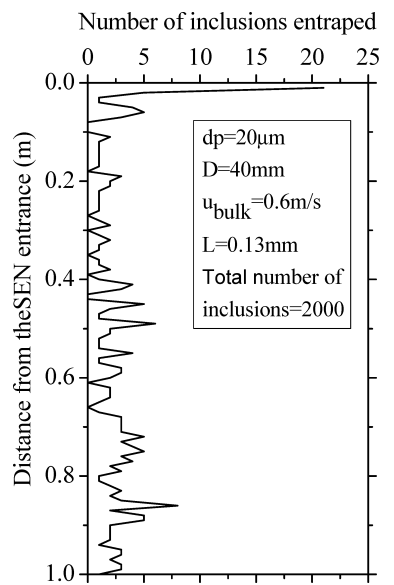

Fig. 12. Distribution of the inclusions entrapped along the nozzle length. 
flow rate in the SEN. The theoretical flow rate of the steel, $Q_{t}$ in $\mathrm{kg} / \mathrm{s}$, in the SEN with a fully open slide gate can be estimate by ${ }^{44)}$ :

$$
Q_{t}=\left(\frac{1}{\beta}+\frac{e_{f}}{6}\right)^{-1 / 2} \rho_{f} \frac{\pi D^{2}}{4}(2 g h)^{1 / 2}
$$

where $\beta$ is a constant, equals 1 for turbulent flow and 0.5 for laminar flow; $e_{f}$ is the friction loss factor, $\sim 0.5$ for the current case; $h$ is the bath depth in the tundish in meter. This equation gives the theoretical flow rate. The real flow rate depends on the casting speed and the billet dimension. Figure 13 shows the theoretical flow rate of the molten steel flowing through the SEN during pouring of billet continuous casting process. The flow rate decreases as the inner diameter of the SEN decreases. A lower bath level in the tundish corresponds to a smaller flow rate. Under the condition of $V_{c}=2.0 \mathrm{~m} / \mathrm{min}, D=40 \mathrm{~mm}, 150 \mathrm{~mm} \times 150 \mathrm{~mm}$ billet, $1.0 \mathrm{~m}$ bath level in the tundish, the slide gate needs to open $\sim 15 \%$ (ratio of opening area to the whole nozzle area) to achieve the flow rate required by the casting speed. As the clogging narrows the inner diameter of the SEN from 40 to $16 \mathrm{~mm}$, the slide gate needs to be open more in order to ensure a constant casting speed. When the slide gate approaches $100 \%$, the flow rate is no longer to ensure the $2.0 \mathrm{~m} / \mathrm{min}$ casting speed any more, then the SEN has to be replaced, or the casting speed have to be reduced.

In the current paper, the inclusions were assumed to be pure alumina $\left(\mathrm{Al}_{2} \mathrm{O}_{3}\right)$, the density of which was assumed to be $3500 \mathrm{~kg} / \mathrm{m}^{3}$, and the total oxygen in the molten steel was in the form of $\mathrm{Al}_{2} \mathrm{O}_{3}$. Thus, the number of inclusions in one kilogram steel can be estimated with the total oxygen content and the size of inclusions, and then the accumulated weight of molten steel that can be poured before the nozzle is blocked can be predicted. The following casting conditions were assumed: $150 \mathrm{~mm} \times 150 \mathrm{~mm}(a=b=0.15 \mathrm{~m}$ for Eq. (28)) billet, $25^{\circ} \mathrm{C}$ superheat, $2.0 \mathrm{~m} / \mathrm{min}$ casting speed, $1 \mathrm{~m}$ bath depth in the tundish, and $1 \mathrm{~m}$ length of the SEN $\left(\mathrm{Al}_{2} \mathrm{O}_{3}-\mathrm{C}\right.$ materials). It is calculated that the thickness of the laminar sub-layer $(L)$ is $0.13 \mathrm{~mm}$ under this condition. In the paper, the inclusions in the molten steel were assumed to be in a single size. When T.O is $30 \mathrm{ppm}$, and diameters of the inclusions are $20 \mu \mathrm{m}$, it is calculated that the number of inclusions is around $5.4 \times 10^{5} / \mathrm{kg}$-steel in the molten steel.

Since the clogging materials include not only inclusions,

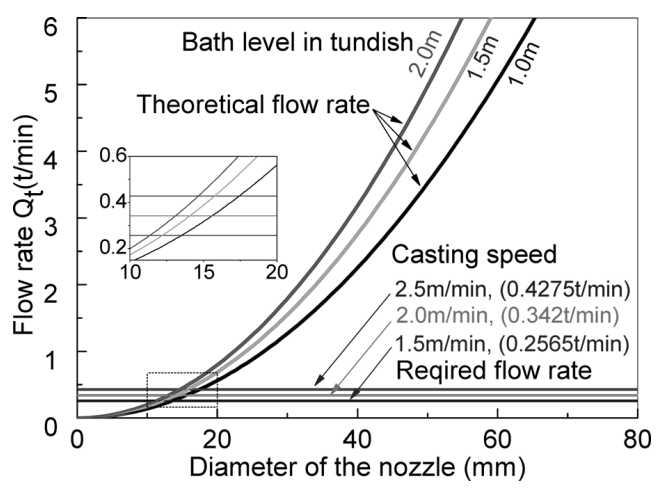

Fig. 13. Estimated theoretical and required flow rate of molten steel during casting with nozzle clogging. but also frozen steel. The fraction of pure inclusions in the clogging materials has to be taken into account. Figure 3 and Fig. 14 show the micro- and macro-structure of the frozen steel in the clogged material.

The relationship between the accumulated weight of molten steel that can be poured and the volume fraction of inclusions in the clogging materials is illustrated in Fig. 15; indicating that the SEN will be blocked faster and less accumulated weight of molten steel can be poured if the volume fraction of the inclusions in the clogging materials is lower. According to the observation by Zhang, ${ }^{2}$ the volume fraction of the inclusions in the clogging materials in the paper was assumed to be $50 \%$. If the non-uniform clogging along the SEN length is not considered, the clogging mate-

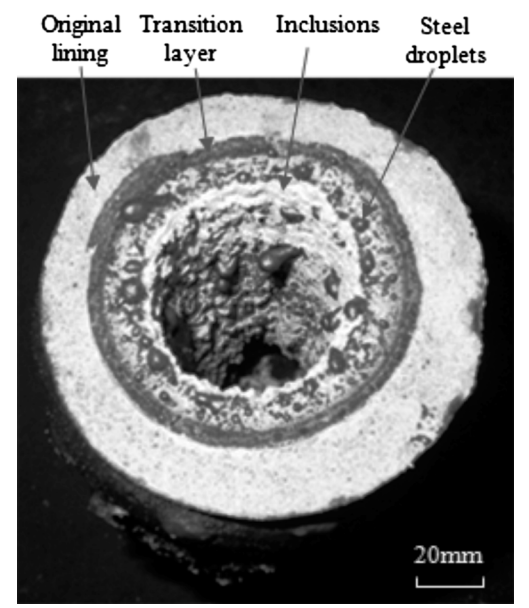

Fig. 14. Macro-structure of inclusions and frozen steel in the clogging material of a SEN.

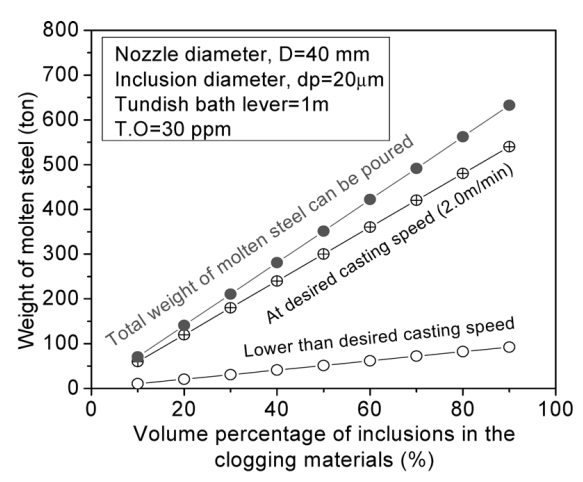

(a) Non-uniform clogging along SEN length

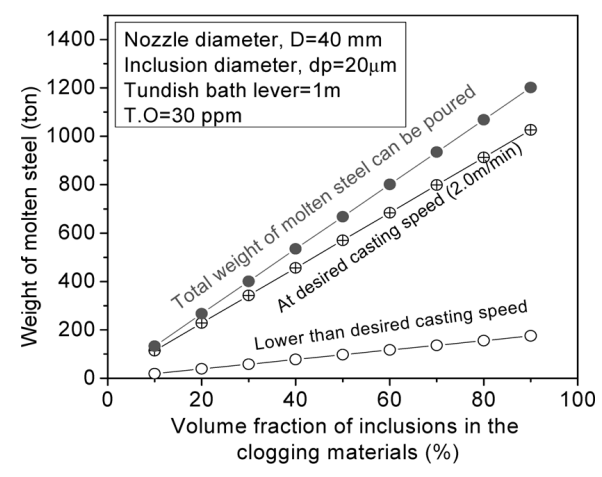

(b) Uniform clogging along the SEN length

Fig. 15. The accumulated weight of molten steel can be poured versus and its affecting factors. 


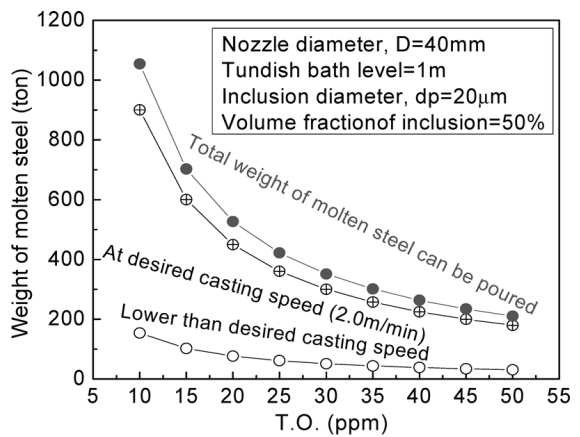

(a) Non-uniform clogging along SEN length

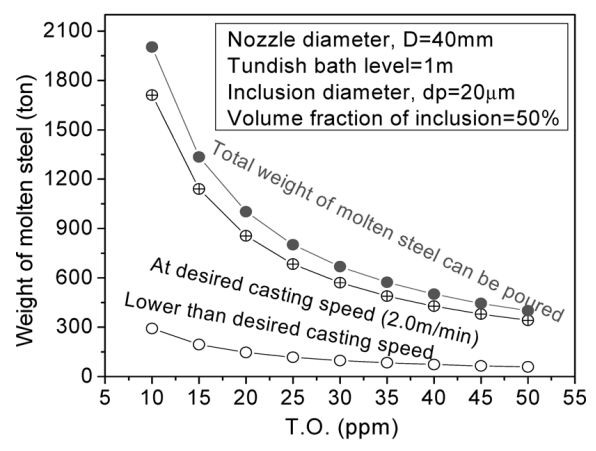

(b) Uniform clogging along the SEN length

Fig. 16. Effect of T.O on the accumulated weight of molten steel can be poured.

rial is assumed to be uniform along the SEN length, then the nozzle is blocked much slower, and thus the accumulated weight of molten steel that can be poured before the nozzle is fully blocked by clogging is much larger, which is not accurate. For example, with the condition of $40 \mathrm{~mm}$ inner diameter of the SEN, $20 \mu \mathrm{m}$ inclusion size, $30 \mathrm{ppm}$ total oxygen, and $50 \%$ inclusions in the clogging materials, around 351 ton steel can be poured for non-uniform clogging along the SEN length, however, around 668 ton steel can be poured if assuming uniform clogging along the SEN length. In order to more precisely predict the accumulated weight of molten steel that can be poured, both volume fraction of the inclusions in the clogging materials and nonuniform clogging along the SEN length should be taken into account.

With more clogging, even though $100 \%$ slide opening fails to assure the casting speed requirement. Then the real casting speed is decided by the bath depth in the tundish and the remaining free inner diameter of the SEN with clogging. Figure 15 also indicates that at this period, the clogging speed becomes very quick, and less than 55 ton steel can be poured.

The effect of the total oxygen in the molten steel (T.O) on the accumulated weight of molten steel that can be poured before the nozzle is fully blocked is illustrated in Fig. 16. Lower T.O implies less inclusions, thus less serious clogging occurs and the casting can be performed longer. If with the following condition: $20 \mu \mathrm{m}$ inclusions, $50 \%$ inclusions in volume in the clogging materials, $2.0 \mathrm{~m} / \mathrm{min}$ casting speed, $40 \mathrm{~mm}$ nozzle inner diameter, and non-uniform clogging along the SEN length, Fig. 16 predicts that for the molten steel with $20 \mathrm{ppm}$ T.O, approximately 527 ton steel can be poured before the nozzle is fully blocked, while for the $40 \mathrm{ppm}$ T.O steel, less than 300 ton steel can be poured.

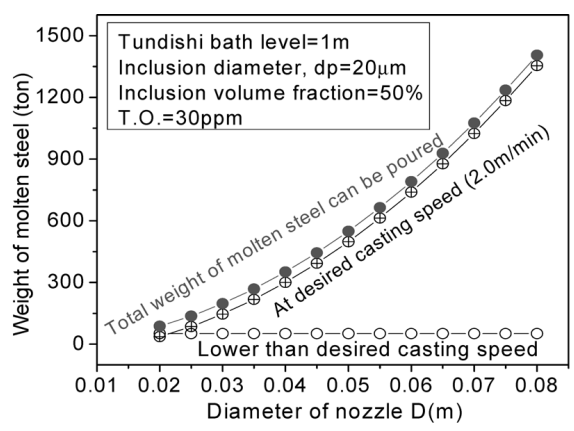

(a) Non-uniform clogging along SEN length

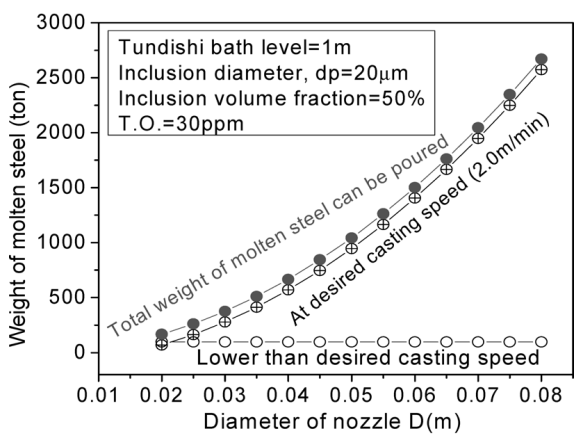

(b) Uniform clogging along the SEN length

Fig. 17. Effect of the inner diameter of the SEN on the accumulated weight of molten steel can be poured.

Figure 16 shows again that most of the molten steel is poured at the desired casting speed, and only a little steel is poured by reducing casting speed. Thus, reducing casting speed is inefficient to solve the issue of SEN clogging.

Figure 17 indicates that larger inner diameter of the SEN pours more molten steel than smaller inner diameter SEN before the SEN is totally blocked. Enlarging the inner diameter of the SEN is one possible measure to pour more steel. However, the diameter of the SEN is limited by the billet dimension and the bottom well and sliding gate system of the tundish. So the core solution to reduce the nozzle clogging is to remove more inclusions during steel refining and in the tundish and then the source for the nozzle clogging is reduced.

\section{Conclusions}

A kinetic model for SEN clogging is developed. The effects of nozzle diameter, casting speed, billet dimension, inclusion size and the total oxygen of the molten steel and several other factors on the clogging of the SEN are taken into account. The following conclusions are obtained:

(1) Inclusions are more easily to be entrapped to the SEN wall under the following conditions: smaller inclusion size, more total oxygen of the molten steel, and smaller casting speed.

(2) Inclusions larger than $100 \mu \mathrm{m}$ are impossible to be entrapped by the nozzle wall, and the entrapment probability increases quickly with decreasing inclusion size if inclusions are smaller than $15 \mu \mathrm{m}$.

(3) The entrapment probability of inclusions is not uniform along the length of the SEN. The entrance locations entrap more inclusions.

(4) The kinetic model developed can predict the accu- 
mulated weight of molten steel that can be poured before the SEN is blocked by the clogging. Changing casting speed or using a large inner diameter SEN can improve the clogging and cast more steel, but removing more inclusions from the molten steel during ladle refining and in the tundish is the key to solve the problem of SEN clogging.

\section{Acknowledgements}

This research is supported by the Research Board Grant, Materials Research Center and Intelligent Systems Center at Missouri University of Science and Technology (Missouri S\&T).

\section{REFERENCES}

1) L. Zhang, Y. Wang and X. Zuo: Metal. Mater. Trans. B, 39B (2008), 534.

2) S. Li, W. Jin, L. Zhang, X. Zuo and Y. Wang: Proc. of AISTech 2008 Iron \& Steel Technology Conf. and Exposition, Warrandale, PA, 1, (2008), 899.

3) H. Matsuura, C. Wang, G. Wen and S. Sridhar: ISIJ Int., 47 (2007), 265.

4) S. Liu, S. Niu, M. Liang, C. Li, X. Zuo, L. Zhang and X. Wang: Proc. of AISTech 2007 Iron \& Steel Technology Conf. and Exposition, AIST, Warrandale, PA, (2007), 771.

5) S. K. Choudhary and S. Chandra: ISIJ Int., 47 (2007), 190

6) R. Sambasivam: Ironmaking Steelmaking, 33 (2006), 439.

7) H. Zheng, W. Chen and Y. Hu: AISTech2004, Warrandale, PA, (2004), 937.

8) J. D. Lavers and L. Kadar: Appl. Math. Model., 28 (2004), 29.

9) P. D. King, L. J. Heaslip, D. Xu, J. D. Dorricott and Q. K. Robinson: ISSTech2003 Conf. Proc., Electric Furnace and Steelmaking, eds., ISS, Warrandale, PA, (2003), 265.

10) S. Devic, R. Galjak and T. Bradaric: Ironmaking Steelmakaing, 30 (2003), 57.

11) A. Cramb, in Making, Shaping and Treating of Steel: Continuous Casting, 5, eds. by A. Cramb, AISE Steel Foundation, Pittsburgh, PA, (2003), 14.1.

12) Y. Vermeulen, B. Coletti, B. Blanpain and J. Vleugels: ISIJ Int., 42 (2002), 1234.

13) B. G. Thomas and H. Bai: 78th Steelmaking Conf. Proc., Iron and Steel Society, Warrendale, PA, (2001), 895.

14) H. Bai and B. G. Thomas: Metall. Mater. Trans. B, 32B (2001), 702.

15) Y. Vermeulen, B. Coletti, P. Wollants, B. Blanpain and F. Haers: Steel Res., 71 (2000), 391.

16) Y. Vermeulen, B. Coletti, B. Blanpain, P. Wollants and F. Haers: 83rd
Steelmaking Conf. Proc., eds., ISS, Warrendale, PA, (2000), 175.

17) G. T. Moulden and R. Sabol: 83rd Steelmaking Conf. Proc., eds., ISS, Warrendale, PA, (2000), 161

18) H. Bai and B. G. Thomas: 83rd Steelmaking Conf. Proc., eds., ISS, Warrendale, PA, Pittsburgh, PA, (2000), 183.

19) L. C. Oertel and A. Costa e Silva: Calphad, 23 (1999), 379.

20) F. L. Kemeny: McLean Symp. Proc., eds., ISS, Warrendale, PA, 83, (1998), 103.

21) V. H. Tapia, R. D. Morales, J. Camacho and G. Lugo: 79th Steelmaking Conf. Proc., eds., ISS, Warrendale, PA, (1996), 539.

22) P. Tassot, A. D. Anselme and J. P. Radot: 78th Steelmaking Conf. Proc., eds., ISS, Warrendale, PA, (1995), 465.

23) K. G. Rackers and B. G. Thomas: 78th Steelmaking Conf. Proc., eds., ISS, Warrendale, PA, (1995), 723.

24) K. Rackers: Masters Thesis, University of Illinois, (1995).

25) N. Bannenberg: 78th Steelmaking Conf. Proc., eds., ISS, Warrendale, PA, USA, (1995), 457.

26) M. Alavanja, R. T. Gass, R. W. Kittridge and H. T. Tsai: 78th Steelmaking Conf. Proc., eds., ISS, Warrendale, PA, (1995), 415.

27) P. M. Benson, Q. K. Robinson and H. K. Park: 76th Steelmaking Conf. Proc., eds., ISS, Warrendale, PA, (1993), 533.

28) S. R. Cameron: 75th Steelmaking Conf. Proc., eds., ISS, Warrendale, PA, (1992), 327.

29) E. Lührsen: 1st European Conf. on Continuous Casting, eds., Associazione Italiana di Metallurgia, Florence, Italy, (1991), 1.37.

30) S. K. Saxena, H. Sandberg, T. Waldenstrom, A. Persson and S. Steensen: Scan. J. Metall., 7 (1978), 126.

31) L. Zhang and B. G. Thomas: ISIJ Int., 43 (2003), 271.

32) S.Dawson: ISS Steelmaking Conf. Proc., 73 (1990), 12.

33) K. Mukai, R. Tsujino, I. Sawada, M. Zeze and S. Mizoguchi: Tetsuto-Hagané, 85 (1999), 307.

34) F. A. Holland eds.: Fluid Flow for Chemical Engineers, ed., Edward Arnold, UK, (1973), 56.

35) J. K.Vennard ed.: Elementary Fluid Mechanics, ed., (1961), 279.

36) C. Crowe and M. Sommerfield ed.: Multiphase Flows with Droplets and Particles, ed., CRC Press LIC, New York, USA, (1998), 71.

37) D. Brickman and P. C. Smith: J. Atmos. Ocean. Technol., 19 (2002), 83.

38) E. Yee and J. D. Wilson: Bound. Layer Meteorol., 122 (2007), 243.

39) H. C. Rodean: Environmetrics, 6 (1995), 659.

40) A. Stohl, C. Forster and A. Frank: Atmos. Chem. Phys., 5 (2005), 2461.

41) I. Kos, D. Belusic and A. Jericevic: GOFIZIKA, 21 (2004), 37.

42) K. N. Volkow: J. Eng. Phys. Thermophysics, 80 (2007), 570.

43) A. S. Berrouk, D. Laurence and J. J. Riley: J. Turbulence, 8 (2007), 1.

44) D. R. Poirier and G. H. Geiger: ed. Transport Phenomena in Materials Processing, ed. by TMS, Warrendale, PA, (1994), 131. 